\title{
Investigation on the Using Behavior of Urban Public Space: A Case Study of Huifeng Park, Linwu County
}

\author{
Xia Jin ${ }^{1, a}$, Liu Ying ${ }^{2, b^{*}}$ \\ 1. 2 School of Design and Art, Xiamen University Of Technology, Jimei, Xiamen, Fujian, China \\ a236859746@qq.com \\ b*1597595641@qq.com
}

\begin{abstract}
In order to study the correlation between urban public space and users' behaviors, and to analyze the users' psychological needs, we take Huifeng Park in Linwu County, Hunan Province as the research object to investigate different types of public space based on behavioral observation methods. Meanwhile, we also compared the using behaviors and different spatial characteristics, and finally summarized the problems existing in the public space of the park, mainly including 1) a poor consideration of users' paschological needs, 2) low utilization rates of some spaces, 3) inadequate ancillary facilities, and 4) problems caused by mental short-cuts. In view of the problems found, we proposed related suggestions and countermeasures for improving and optimizing the design, which provide reference value for future research on the use of public space.
\end{abstract}

Keywords: public space, behavioral observation methods, spatial characteristics, using behavior, psychological needs

\section{城市公共空间使用行为调查研究 以临武县迴峰公园为例}

\author{
1.2 厦门理工学院设计艺术学院, 集美, 厦门, 福建, 中国 \\ a236859746@qq.com \\ b*1597595641@qq.com
}

夏 锦 $1, \mathrm{a}$, 刘 溁 $2, \mathrm{~b}^{*}$

\section{摘要}

为研究城市公共空间与使用者行为之间的关联, 剖析使用者心理需求, 以湖南省椰州市临武县迴峰公园作 为研究对象, 采用行为观察法进行分析, 并对公园中不同类型的公共空间进行调研, 对比不同空间特性的使 用行为和差异总结出公园公共空间中存在的问题有：1）考虑不到主要使用人群的心理需求；2）部分空间使 用率低；3）辅助配套设施不到位；4）因捷径效应产生的问题。并针对发现的问题, 提出了改进和优化设计的 建议和对策，为今后公共空间使用行为研究提供参考价值。

关键词: 公共空间, 行为观察法, 空间特性, 使用行为, 心理需求

\section{1. 前言}

城市公园是城市居民户外进行休闲活动的重要 载体，在人们的日常生活中扮演着十分重要的角 色。然而在城市公园设计领域里, 早期的城市公园 公共空间规划设计过程中，设计师受现代主义思想 的影响, 他们则强调其作品的功能优先、几何形式
感、模式化设计以及艺术审美情趣等，将个人价值 观、文化信念和审美观强加于使用者，忽略了使用 者在城市公园公共空间中日常行为活动特征的本质 需求，以至于使设计师与公园使用者长期处于矛盾 的对立面 ${ }^{[1]}$ 。因此从使用者的使用行为特征出发, 探究城市公园公共空间与使用者行为活动的关系, 总结出影响公园使用者行为活动特征的空间要素并 
对其进行优化设计, 城市公园才能更好地服务于城 市居民, 并为今后的城市公园设计提供借鉴意义。

\section{2. 文献探讨}

\section{1 研究使用者行为的作用}

研究使用者行为对剖析使用者心理需求有很大 作用, 比如处于休息中的人们心理状态会逐渐放 松, 此时人们的行为不希望受到外界干扰 ${ }^{[2]}$, 而在 公共空间设计中, 往往欠缺对空间细节的考虑。基 于使用者行为的公共空间设计研究在国内还没有得 到相应的重视 ${ }^{[3]}$ ，当前许多公共空间的 “人性化” 设计只针对青年群体, 忽略了居住中主要使用公共 空间的儿童和老年人群体 ${ }^{[4]}$, 但是对于这些特殊人 群的使用行为研究也十分重要, 因此, 采用行为观 察法对公共空间中的使用者进行行为调查, 是目前 较为科学的研究方式, 能为公共空间设计研究提供 更好的依据。

\section{2 公共空间研究的意义}

公共空间的提供被视为缓解城市化挑战的可行 办法, 其是居民日常休闲活动的主要场所, 并有助 于城市居民之间的交流, 城市公共空间平等对公众 开放和服务，不仅仅为居民提供交往和交流的场 所, 促进人与人之间的交流, 同时能够提升居民幸 福感以及改善城市形象 ${ }^{[5]}$ 。真正的 “公共空间” 是 人们群体的活动, 以及这些使用与发言的人, 他们 为此目的所使用的空间, 这就是探讨公共空间的重 要意义。以往的公共空间注重提高经济效益方面的 意义, 从而导致了大量公共空间资源浪费 ${ }^{[6]}$, 并且 国内近年来才开始重视公共活动空间的关键作用, 因此对公共空间的调查研究更具现实意义 ${ }^{[7]}$ 。

\section{3 不同公共空间特性的差异性}

不同类型的公共空间使用行为也不同，公共空 间一方面为人们提供公共活动场所; 另一方面, 它 也可以对人们的活动起到推动或限制的作用 ${ }^{[8]}$ 。例 如在城市的各类型公共空间中, 草坪或小广场为居 民健身、跳广场舞、打篮球等活动提供了合适的场 地, 公园建筑物周边则为居民提供休息和游览活动 的场所, 文章以临武县迴峰公园为研究对象, 分析 了三种不同类型的公共活动空间中人们的使用行为 存在的差异。

\section{4 城市公园优化设计的必要性}

未来的城市发展思路将是公园与城市的融合发 展 $^{[9]}$, 公共空间因其利用频率较高, 与城市居民的 日常生活关系密切, 因而研究公共活动空间如何促 进居民的健康有重要的现实意义 ${ }^{[10]}$ 。由于部分公共 空间缺少对人在公共空间的心理、行为与互相交往
等设计细节方面考虑，造成大量公共空间不能满足 市民的需求, 而不能被充分利用起来 ${ }^{[11]}$, 因此公园 中有必要关注设计细节, 并创建能够响应不断变化 的公共空间活动的设计, 在这种情况下, 通过深入研 究才能创造出能更好满足为市民服务的城市公共空 间设计。

\section{3. 研究设计}

\section{1 基地环境分析}

迴峰公园位于湖南省椰州市临武县, 公园周边 分布小区、学校、商店与车站等基础设施, 人流量 较大, 公园周边的商店大部分位于公园主入口的道 路旁, 为周边居民与游客提供便利, 学校分布在公 园的东北方向, 放学后与节假日有大量的儿童与家 长前往公园活动。

迴峰公园历史短, 基础设施整体也相对较新, 设施的类型以凉亭、长廊、木塔等富有历史感的建 筑元素为主。由于园区范围较大, 本研究主要选取 公园三个具有代表性的活动空间（图1）, 包括儿童 活动草坪、健身广场与休闲广场三个部分为重点调 查对象，并拍摄现场照片（图2-4），对三种不同类 型公共空间进行描述, 绘制空间平面草图（图5）, 以便于更好的对活动空间进行调查与分析。

基地空间描述：A儿童活动草坪: 草坪由圆形围 合, 其位置位于迴峰公园的南部, 草坪南面有较长 的方石, 其作用为增加观赏性的同时还可以用作休 闲坐登; 草坪另一侧由人行道路围合, 道路一旁还 设有休闲座椅。 $\mathrm{B}$ 健身广场: 该广场离儿童活动草坪 较近, 其主要功能是提供人们锻炼身体的场所, 广 场左边是我鸟卵石组成的圆形空间, 老年人喜欢光脚 踩在上面, 广场中间是用来锻炼身体的一些设备; 广场右侧是一个沙坑, 吸引一些小孩在里面玩要。C 休闲广场: 该广场是迴峰公园地势最高的广场, 也是 视野最开阔的广场, 人流量大, 但对于腿脚不便的 老年人有些困难, 需要花费很多力气才能达到; 该 广场平日的晚上和周末节假日期间人流量最大。

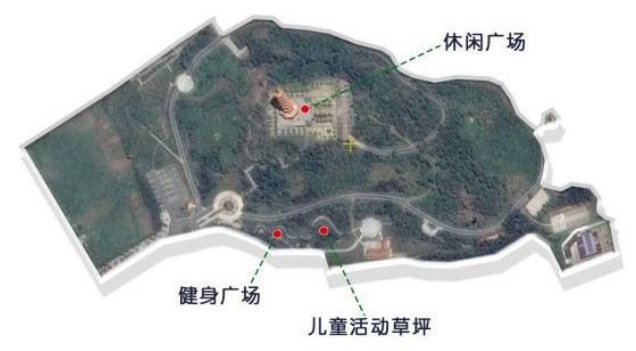

图1 迴峰公园鸟瞰图 


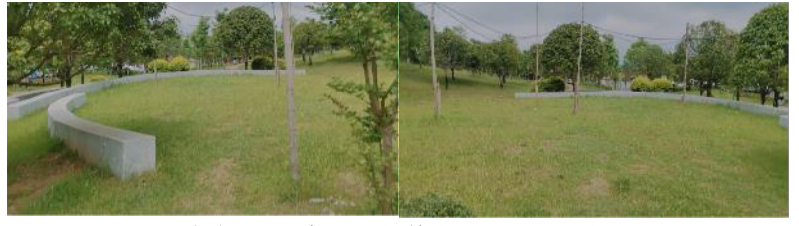

图2 儿童活动草坪现场照片

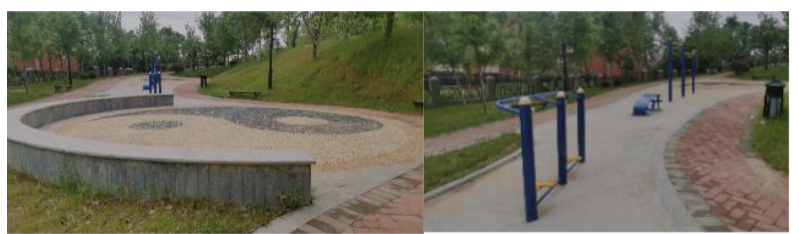

图3 健身广场现场照片

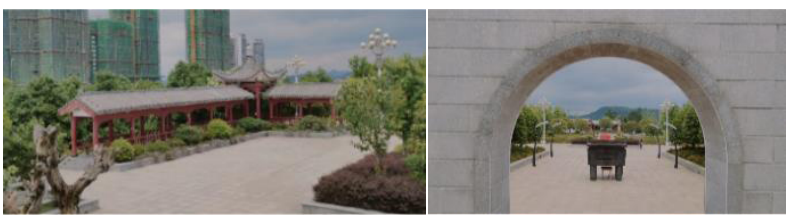

图4 休闲广场现场照片

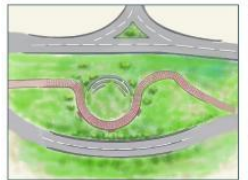

儿童活动草坪

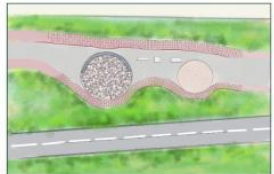

健身广场

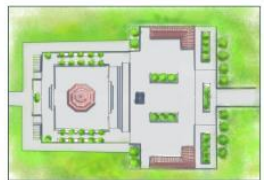

休闲广场
图5 三个不同空间类型平面图

\section{2 行为观察法}

文章研究方法主要采用行为观察法, 根据现场 观察并记录下三个公共活动空间中使用者的使用行 为, 将调查结果进行统计分类, 不同使用时段的使 用状况进行分析, 整合比对以理清不同类型公共活 动空间中使用行为的不同特征。

观察时间：本研究调研时间为 2020 年 8 月至 11 月 期间, 该期间为疫情防控的特殊期间, 将使用行为 的观察时间分为平日和假日两种类型。分别从早上 七点至晚上九点进行观察, 每一个小时观察一次, 三个空间每次观察 20 分钟, 调查结果以每两个小时 为一个时段。

观察内容: 观察内容包括对三个不同空间的空 间特征、周边环境，以及不同时段使用者的使用行 为和场所分布进行观察记录。透过观察场地并绘制 场地平面图, 在图中标注场地周围的环境, 如主要 建筑、公园设施、交通路线等情况, 同时还包含场 地的各种要素——边界、入口、道路、小型的空 地、健身设施以及主要的绿地。最后, 通过对现场 记录进行整理, 对不同时段、不同类型的公共活动 空间使用行为做分析总结。

\section{2.1 行为痕迹记录}

在观察日的最后, 进行一次行为痕迹记录, 记
录结果显示主要有三种的基本情况：1）磨损型痕 迹, 如休息椅上剥落的油漆, 公共设施下松动的铺 材, 穿越草坪踩的小路等, 这些都反映了人们对公 共设施的使用情况；2）累积型痕迹例如（果皮、烟 头、啤酒瓶、塑料袋、动物粪便) 等, 观察到的是 渐渐累积起来的物质, 因此表明人们在场地上发生 过类似的活动；3）值得注意观察也是最容易被忽视 的, 在某些地方该有却没有的痕迹, 如游戏场上的 沙坑中没有脚印，没有挖出的沙洞或游戏过的 “残 局” 等痕迹。因此这些痕迹线索, 都表明可能是因 为使用率太高的缘故, 而缺少行为痕迹的场所则说 明使用率不高或维护水平很高。

\section{3 具体案例调查分析}

根据行为观察记录法, 统计出一天当中不同时 段内，不同空间特性的使用行为人数，并对该记录 数据进行搜集整理, 对统计结果进行分析提出问题 及建议夜间（表1）。

\section{3. 1 儿童活动草坪调查结果}

儿童活动草坪是使用率比较高的公共活动空 间, 无论平日还是假日, 虽然草坪内公共设施非常 少，但这里靠近居民居住区，其草坪绿化程度比较 高、活动面积大, 能满足周边居民活动的需求。调 查结果显示大约有 $80 \%$ 的行为为穿越, 调查得出草坪 是小区学生上下学的捷径路段, 穿越的人流量非常 多，尤其在上下学时间段；相比之下，在假日期间 学生休息, 所以穿越行为大量减少。由于, 假日期 间是上班族和学生的休息时间, 所以这部分人群很 大几率会选择到公园内活动, 因此, 在公园内其他 活动空间使用行为次数增长。

根据行为痕迹观察记录, 场地垃圾桶沿道路分 布距离远，垃圾较多; 同时，草地上有大部分被踩 踏以及使用过的痕迹, 草坪内没有其他公共设施, 只有草坪周围分布有部分的座椅, 所以人们喜欢席 地而坐, 坐在草坪上聊天成为人们放松休闲的一种 常态。

\section{3.2 健身广场调查结果}

健身广场与儿童活动草坪地理位置相邻, 但空 间特性区别大，广场较草坪的使用率更高，该广场 面积不大，但有可以运动的公共设施，例如一些健 身器材、沙坑等。由于广场靠近居住小区, 在节假 日期间，平常工作的人会在该广场锻炼身体，进行 做操、跑步和散步等活动, 锻炼的行为在假日呈增 长状态, 另一种情况可能由于受疫情关系影响, 人 们对身心健康的需求增强。

据行为痕迹记录, 该广场设施磨损的程度大, 说明广场内公共设施的使用频率较高, 但广场内沙 坑游戏过的痕迹少, 经过观察发现沙坑内有很多动 
物的粪便, 以及塑料袋, 严重影响了沙坑的环境卫 生, 导致沙坑使用率较低。

\subsection{3 休闲广场调查结果}

休闲广场的地势位置较高, 空间穿越率较低, 其主要行为是散步、游玩和锻炼, 休闲广场上大部 分人以拍照和参观为目的; 特别在假日期间，是公 园人最多的时候, 很多家长会选择晚上带孩子到公
园里游玩, 尤其是夏季的夜晚, 休闲广场上非常凉 爽，因此人们的空间活动行为更加复杂，许多人喜 欢坐在广场周边、隐蔽的凉亭及一些廊角的位置。

据行为痕迹观察记录, 迴峰塔周围的烟头、塑 料袋非常多, 人们不喜欢走到很远的地方丢垃圾, 而塔周围并没有设立足够的垃圾桶; 另外，塔身有 很多被划过的痕迹，还有攀爬栏杆的脚印，这些现 象都对维护公共空间环境造成不良影响。

表1 公园三种不同类型空间每时段使用行为分类统计表（单位：人）

\begin{tabular}{|c|c|c|c|c|c|c|c|c|c|c|c|c|c|c|c|c|c|c|c|c|c|c|c|c|c|}
\hline \multirow{2}{*}{\multicolumn{2}{|c|}{$\begin{array}{c}\text { 人数统计 } \\
\text { (人) }\end{array}$}} & \multicolumn{8}{|c|}{ 儿童活动草坪 } & \multicolumn{8}{|c|}{ 健身广场 } & \multicolumn{8}{|c|}{ 休闲广场 } \\
\hline & & \multirow{2}{*}{$\begin{array}{c}\text { 锻 } \\
\text { 炼 } \\
6\end{array}$} & \multirow{2}{*}{$\begin{array}{c}\text { 散 } \\
\text { 步 } \\
2\end{array}$} & \multirow{2}{*}{$\begin{array}{l}\text { 穿 } \\
\text { 越 } \\
57\end{array}$} & \multirow{2}{*}{ 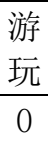 } & \multirow{2}{*}{$\begin{array}{c}\text { 带 } \\
\text { 娃 } \\
0\end{array}$} & \multirow{2}{*}{\begin{tabular}{|c}
$\begin{array}{l}\text { 聊 } \\
\text { 天 }\end{array}$ \\
0
\end{tabular}} & \multirow{2}{*}{$\begin{array}{l}\text { 约 } \\
\text { 会 } \\
0\end{array}$} & \multirow{2}{*}{$\begin{array}{l}\text { 合 } \\
\text { 计 } \\
65\end{array}$} & \multirow{2}{*}{\begin{tabular}{|l|}
$\begin{array}{l}\text { 锻 } \\
\text { 炼 } \\
12\end{array}$ \\
\end{tabular}} & \multirow{2}{*}{$\begin{array}{c}\begin{array}{l}\text { 散 } \\
\text { 步 }\end{array} \\
5 \\
\end{array}$} & \multirow{2}{*}{$\begin{array}{l}\text { 穿 } \\
\text { 越 } \\
51\end{array}$} & \multirow{2}{*}{ 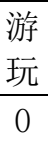 } & \multirow{2}{*}{$\begin{array}{c}\text { 带 } \\
\text { 娃 } \\
0\end{array}$} & \multirow{2}{*}{$\begin{array}{c}\text { 聊 } \\
\text { 天 } \\
0\end{array}$} & \multirow{2}{*}{$\begin{array}{l}\text { 约 } \\
\text { 会 } \\
0\end{array}$} & \multirow{2}{*}{$\begin{array}{l}\text { 合 } \\
\text { 计 } \\
68\end{array}$} & \multirow{2}{*}{$\begin{array}{l}\text { 锻 } \\
\text { 炼 } \\
12\end{array}$} & \multirow{2}{*}{$\begin{array}{c}\text { 散 } \\
\text { 步 } \\
5\end{array}$} & \multirow{2}{*}{$\begin{array}{c}\begin{array}{c}\text { 穿 } \\
\text { 越 }\end{array} \\
0\end{array}$} & \multirow{2}{*}{$\begin{array}{c}\text { 游 } \\
\text { 玩 } \\
0\end{array}$} & \multirow{2}{*}{$\begin{array}{c}\text { 带 } \\
\text { 娃 } \\
0\end{array}$} & \multirow{2}{*}{$\begin{array}{c}\text { 聊 } \\
\text { 天 } \\
0\end{array}$} & \multirow{2}{*}{$\begin{array}{l}\text { 约 } \\
\text { 会 } \\
0\end{array}$} & \multirow{2}{*}{$\begin{array}{l}\text { 合 } \\
\text { 计 } \\
17\end{array}$} \\
\hline & & & & & & & & & & & & & & & & & & & & & & & & & \\
\hline & 假日 & 0 & 2 & 4 & 0 & ( & 0 & 0 & 14 & 23 & 5 & 4 & 0 & 0 & 5 & 0 & 37 & 12 & 5 & 0 & 1 & 0 & 2 & 0 & 20 \\
\hline & 平日 & 4 & 1 & 27 & 10 & 8 & 2 & 2 & 54 & 10 & 7 & 23 & 1 & 8 & 2 & 0 & 51 & 23 & 16 & 5 & 5 & 2 & 2 & 4 & 57 \\
\hline & 假日 & 4 & 1 & 13 & 1 & 14 & 2 & 2 & 37 & 29 & 18 & 24 & 1 & 8 & 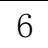 & 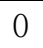 & 86 & 30 & 16 & 10 & 24 & 13 & 2 & 4 & 99 \\
\hline & 平日 & 0 & 1 & 46 & 0 & 1 & 0 & 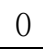 & 48 & 2 & 2 & 51 & 0 & 2 & $\sigma$ & $\sigma$ & 8 & 2 & 2 & 2 & 2 & 0 & 0 & 0 & 8 \\
\hline & 假日 & 0 & 1 & 23 & 0 & 0 & 0 & 0 & 24 & 8 & 2 & 12 & 0 & 2 & U & 0 & 24 & 12 & 2 & 2 & 14 & 0 & 0 & 0 & 30 \\
\hline & 平日 & 0 & 0 & 58 & 0 & 0 & 2 & 0 & 60 & 0 & 1 & 46 & 0 & 0 & 2 & ( & 49 & 0 & 1 & 0 & 7 & 0 & 2 & 0 & 10 \\
\hline & 假日 & 0 & 0 & 13 & 0 & 0 & 2 & 0 & 15 & 3 & 6 & 8 & 0 & 0 & 2 & O & 19 & 0 & 1 & 0 & 7 & 0 & 2 & 0 & 10 \\
\hline & 平日 & 0 & 17 & 27 & 2 & 6 & 4 & 0 & 56 & 9 & 12 & 28 & 2 & 7 & 4 & 0 & 62 & 25 & 12 & 7 & 9 & 3 & 4 & 0 & 60 \\
\hline & 假日 & 4 & 5 & 26 & 35 & 12 & 16 & 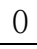 & 98 & 11 & 24 & 21 & 24 & 7 & 4 & 0 & 91 & 25 & 30 & 14 & 51 & 20 & 19 & 8 & 167 \\
\hline & 平日 & 0 & 2 & 52 & 0 & 0 & 0 & 0 & 54 & 2 & 6 & 47 & 0 & 0 & 0 & 0 & 55 & 12 & 6 & 4 & 18 & 0 & 0 & 6 & 46 \\
\hline & 假日 & 0 & 2 & 4 & 0 & 0 & 0 & 0 & 6 & 26 & 6 & 14 & 0 & 2 & - & 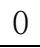 & 48 & 12 & 36 & 12 & 54 & 12 & 25 & 6 & 157 \\
\hline & 平日 & 0 & 19 & 39 & 14 & 4 & 5 & 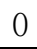 & 81 & 13 & 10 & 33 & 2 & 4 & $J$ & 4 & 69 & 22 & 18 & $J$ & 22 & 4 & 5 & 12 & 88 \\
\hline & 假日 & 0 & 3 & 22 & 25 & 8 & 5 & 0 & 63 & 24 & 10 & 24 & 13 & 4 & 8 & 2 & 85 & 26 & 32 & 28 & 36 & 15 & 37 & 15 & 189 \\
\hline
\end{tabular}

\section{4 小结}

公共空间使用率的高低与周边环境、空间位 置、人流量等因素有着密切关系，其中方便易达性 是保证场所使用率和活力的重要因素。由于活动草 坪和健身广场靠近居住小区，人流量大，所以日常 使用率高, 而休闲广场使用率会随节假日的变化而 变动（表2）。在观察中发现, 公共空间的边界以及
区域与区域之间的过渡区往往成为活动的密集区, 这些区域的特点是具有安全感, 既可以休息停留, 又不会被其他使用者观察发现, 个人空间私密性 高, 并能观察到周边其他人的行为活动。因此, 本 研究发现公园中许多使用者喜欢处于边缘闲坐, 这 种现象表明空间活动使用中存在着边界效应, 影响 使用者的使用行为活动。

表 2 使用行为调查人数统计表（单位: 人)

\begin{tabular}{|c|c|c|c|c|c|c|c|c|c|c|c|c|c|c|c|c|c|c|c|c|c|c|c|c|c|}
\hline \multirow{3}{*}{\multicolumn{2}{|c|}{$\begin{array}{c}\text { 人数统计 } \\
\text { (人) }\end{array}$}} & \multicolumn{8}{|c|}{ 儿童活动草坪 } & \multicolumn{8}{|c|}{ 健身广场 } & \multicolumn{8}{|c|}{ 休闲广场 } \\
\hline & & 锻 & 散 & 穿 & 游 & 带 & 聊 & 约 & 合 & 锻 & 散 & 穿 & 游 & 带 & 聊 & 约 & 合 & 锻 & 散 & 穿 & 游 & & 聊 & 约 & 合 \\
\hline & & 炼 & 步 & 越 & 玩 & 娃 & 天 & 会 & 计 & 炼 & 步 & 越 & 玩 & 娃 & 天 & 会 & 计 & 炼 & 步 & 越 & 玩 & 娃 & 天 & 会 & 计 \\
\hline \multirow{3}{*}{$\begin{array}{l}\text { 平 } \\
\text { 日 }\end{array}$} & 使用者 & 10 & 42 & 302 & 26 & 19 & 13 & 2 & 414 & 48 & 43 & 279 & 5 & 21 & 13 & 2 & 411 & 96 & 100 & 23 & 70 & 9 & 13 & 22 & 333 \\
\hline & / 人次 & & & & & & & & & & & & & & & & & & & & & & & & \\
\hline & $\begin{array}{c}\text { 百分比 } \\
/ \%\end{array}$ & 2.4 & 10.2 & 73 & 6.3 & 4.5 & 3.1 & 0.5 & & 11.6 & 10.5 & 68 & 1.2 & 5 & 3.2 & 0.5 & & 29 & 30 & 6.7 & 21 & 3 & 4 & 6.3 & \\
\hline & 使用者 & 16 & 14 & 105 & 61 & 34 & 25 & 2 & 257 & 124 & 71 & 107 & 38 & 23 & 25 & 2 & 390 & 129 & 132 & 66 & 229 & 64 & 87 & 36 & 743 \\
\hline & / 人次 & & & & & & & & & & & & & & & & & & & & & & & & \\
\hline & $\begin{array}{c}\text { 百分比 } \\
/ \%\end{array}$ & 6.2 & 5.4 & 41 & 23.7 & 13.2 & 9.7 & 0.8 & & 32 & 18.2 & 27 & 9.8 & 6 & 6.4 & 0.6 & & 16.8 & 17 & 10.3 & 30 & 10 & 11 & 4. 9 & \\
\hline
\end{tabular}




\section{4.1 不同类型公共活动空间使用行为分析}

通过以上分析, 并结合观察结果对三个不同空 间类型的不同使用行为进行归纳整理，根据绘制的 三个不同空间平面草图，制作空间活动路径示意图 进一步了解使用者行为（图6）。

儿童活动草坪: 1) 儿童活动草坪地势平坦, 大 片草坪且树木较多, 可以起到很好的遮阳作用, 小 朋友喜欢在石椅之间跑来跑去或者站在石椅上活 动, 大人会坐在石椅上休息, 观看小朋友玩要; 2) 空间中没有大量公共设施等阻挡物, 是公园周边小 区学生上下学的捷径道路, 穿越行为最多, 人流大 部分往来在学校和小区之间；3）草坪周边分布有景 观长石和长椅, 可供人们休息及观察, 人群大部分 集中在上午、傍晚和午后时段。

健身广场: 1) 广场地势平坦, 视野较开阔, 天 气晴朗的时候可以给小孩和老人提供活动的场所, 家长坐在周围休息或坐在沙坑周围观看小孩游戏, 家长也会带小孩使用公共健身设施；2）因为健身广 场与儿童活动草坪相邻, 所以空间穿越行为相似。

3）健身广场空间开阔可以为人们提供足够的运动空 间, 观察发现, 多数老人会踩在鹅卵石上和在广场 空地上做操或使用公共设施锻炼。

休闲广场：1）该空间是公园重要的景点, 视野 广阔草丛多, 活动范围大, 人群主要沿周围灌木丛 散步游走, 人们喜欢穿梭在广场中来回观赏散步; 2) 广场上绿化程度大, 有很多树坛给人们提供休息 的场地, 通常人们会坐在休息椅上、长廊里或者树 坛上休息聊天。

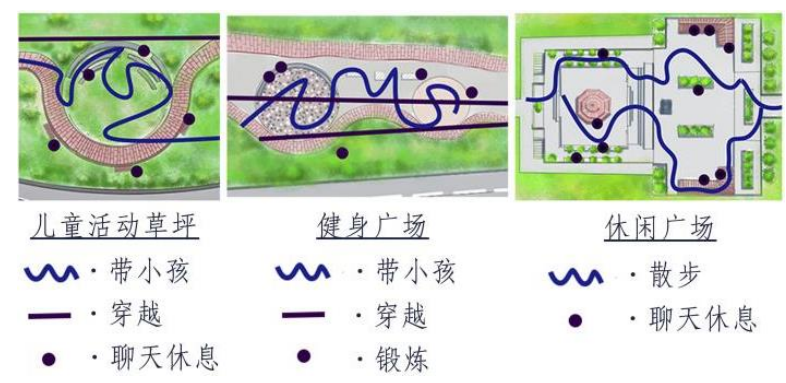

图6 空间行为活动路径示意图

\section{4. 问题与建议}

\section{1 老人与儿童公共设施不完善}

在公共空间设计中往往考虑不到老人与儿童这 类主体使用者的喜好及行为特征, 只是简单的划出 一个区域或摆上几个体育器械, 这样的设计不能吸 引使用者。大部分空间设计往往考虑不周全, 所以往 往表现在空间上的不足和缺少锻炼后可供休息时的 座登。在儿童公共活动空间设计中, 大多设计也都 是简单地划出一块场地, 这些空间简单、乏味, 而
对于儿童身心健康和成长更有利的是丰富且有创造 力、有探索性的公共活动空间。

\section{2 空间使用率低}

公共空间内使用率低的情况主要有三种：1）空 间区位位置偏僻, 通常人们会因距离和交通等因 素，对不容易到达的公共空间选择放弃，从而降低 了空间使用率，其中休闲广场因地理位置高所以在 平日的使用率较低, 人们通常在节假日参观游览;

2) 人们对空间环境差的场所产生抗拒心理，会导致 使用率降低, 健身广场的沙坑因动物粪便和随手丢 弃的垃圾, 人们几乎没有参与到沙坑的活动, 所以 对空间环境的维护是影响使用率的重要因素。3）因 边界效应产生的使用行为, 人们经常选择那些视野 开阔, 同时又有安全感的空间, 对空间的中心位置 和全面开放的空间产生抗拒，因此会降低这些空间 的使用率，在休闲广场中心处的几个座椅经常空无 一人，所以设计中应考虑到使用者的心理需求，减 少空间资源的浪费。

\section{3 辅助配套设施不到位}

具体问题：1）休闲广场里部分垃圾桶存在位置 放置较隐蔽、被树林遮挡等问题, 垃圾桶很难被使 用者发现，导致随手乱扔的情况，每隔50米需设置 一个垃圾桶, 垃圾桶放置位置应明显, 这样有利于 提高垃圾桶的使用率，避免浪费。2）休闲广场里大 部分居民喜欢坐在树池, 但树池不符合使用者人体 工程学, 坐久了会疲㤂。因此可将树池与座椅结合 起来, 既节省了座椅数量也满足人们对座椅使用的 心理需求。3）由于当地居民出行喜欢骑摩托车和自 行车, 广场内有出现交通工具随意停放的现象, 影 响公园美观和秩序, 应在公园里规划非机动车的停 车位, 减少非机动车乱停放的现象。4）休闲广场上 一些流动商贩会在公园里随处推车售卖一些水、零 食等, 但这对公园的美观和环境产生影响, 增加公 园里垃圾数量。因此在公园里设置一些固定的售卖 推位, 并在周围增加垃圾桶数量, 给在公园游玩的 人提供一些需求便利, 也起到对公园环境保护的作 用。

\section{4 捷径效应}

迴峰公园捷径效应的现象主要有三种：1）在活 动草坪内由于人们的穿越行为一些草坪被破坏, 可 以适当的根据人们的行为活动在已经被破坏的草坪 上铺设石板，为居民提供便利的同时，也可以美化 道路环境；2）天气晴朗的时候，附近的居民会在公 园内晾晒被子, 这些行为的出现, 同时也说明小区 内的光线与晾晒衣环境不足。因此, 建议在不影响 公园环境的同时, 可以在靠近小区并且视野开阔、 阳光充足的地方设置晾衣架杆, 提高居民幸福指 数；3）休闲广场的迴峰塔周围因不便设置垃圾桶, 
人们对不远处垃圾桶产生抗拒, 所以捷径效应心理 会有随手丢弃垃圾的行为, 因此需要在建筑周围设 立明令禁止的标语。

\section{5. 结论}

综上所述，迴峰公园三个不同类型空间，因区 位位置、空间特性和使用时间的不同，所产生的使 用行为与使用率也有所不同。通过对三个不同类型 空间行为分析, 并发现问题给予一些改善建议, 对 公园环境提出: (1)完善老人和儿童公共活动空间设 施; (2)空间环境问题是影响使用率的重要因素, 因 对空间环境加大维护力度; (3)空间设计中应考虑到 使用者的心理需求, 减少空间资源浪费; (4)垃圾桶 需每隔50米设置一个, 放置位置应明显; (5)将树池 与座椅结合起来, 提高空间利用率; (6)在公园内规 划非机动车的停车位; (7)在公园内设置一些固定的 摊位, 在其周围增加垃圾桶数量; 8)在已经被破坏 的草坪上铺设石板, 美化道路环境; (9)在靠近小区 视野开阔阳光充足的地方设置晾衣架杆; (10)在迴峰 塔周围设立明令禁止的标语。本研究对不同类型空 间的使用行为进行分析，根据使用者的行为剖析使 用者心理需求, 从而发现公共空间中不合理现象并 提出改善建议, 进行优化公园环境设计, 希望为今 后公共空间使用行为研究提供参考价值。

\section{项目基金}

福建省中青年教师教育项目 ( JAS21298) 、厦门市留学科研项目 (50319003)

\section{REFERENCES}

[1] Zhou L X, Li C Y. Differences and Changes in Urban and Rural Public Spaces Environmental Design Thinking. Design. 2020; 33(19): 89-91.

[2] Gao X, Wang S, Wang J, Wu Z. Public Space Design of Outpatient Buildings Based on the Behavior and Psychological Needs of Users. Architectural Journal. 2012; (S2): 201-204.

[3] Chen Y Y, Liu W B. Research on Large-scale Urban Public Space Design: A Perspective from User Behavior and the Case Study of North Central Axis Square, Shenzhen. Chinese Landscape Architecture. 2015; 31(07): 108-112.

[4] Li Q T. Research on Spatial Correlation between Resident Behavior and Residential Activities Based on Behavioral Observation Methods. Hefei University of Technology; 2017.

[5] Yue H Y. Research on Urban Public Space Design Based on Interaction. Design. 2020; 33(16): 144147.
[6] Su G Z. Research to Understand Public Space through the Perspective of People' s Behavior The Case Study of Taikooli Sanlitun in Beijing. Chinese Landscape Architecture. 2015; 31(12): 7579.

[7] Chen Y Y, Liu T. Exploring the Factors that Attract People to Visit Public Spaces of Communities A Case Study of the OCT, Shenzhen. Architectural Journal. 2016; (02): 107-112.

[8] Chen Y, He Y, Wang K. Research on the Characteristics and Vitality of the Small Towns' Public Space in North Zhejiang Province. Architecture \& Culture. 2018; (09): 94-96.

[9] Lin H. The Future City Development Thought is the Park and the City Fusion Development - - Lin Hai on Environmental Design. Design. 2020; 33(16): 55-61.

[10] Feng Q W. Health-oriented planning and design of community parks - A case study of jiulongpo district, Chongqing. Beijing Forestry University; 2019.

[11] Zheng M. Research on Urban Public Space Design and Human Behavior. Nanjing Agricultural University; 2005. 